\title{
Comparison of the Germination and Outgrowth of Spores of Bacillus cereus and Bacillus polymyxa
}

\author{
By W. A. HAMILTON AND J. M. STUBBS \\ Unilever Research Laboratory, Colworth House, Sharnbrook, Bedford
}

(Accepted for publication 21 November 1966)

\section{SUMMARY}

During germination of Bacillus cereus spores, the cortex was lost completely, but with $B$. polymyxa spores there was no apparent alteration in the cortex structure. On the other hand, the quantities of dipicolinic acid, calcium and mucopeptide, measured as hexosamine, released from germinating $B$. polymyxa spores were similar to those released from germinating $B$. cereus spores. It appears that only about $30 \%$ of the mucopeptide of these species is involved in the maintenance of spore dormancy. The solubilization of the spore dipicolinic acid, calcium and mucopeptide during germination only accounted for about half of the loss of dry weight from the spores. During the outgrowth of $B$. cereus, the spore coats dissolved away at one pole and the vegetative form grew out, leaving only fragments of the spore integument free in the medium. Bacillus polymyxa grew when the largely unaltered coat and cortex layers of the spore split open at the organism's equator.

\section{INTRODUCTION}

The germination of Bacillus spores is characterized by the loss of phase brightness and heat resistance, and a decrease of $30 \%$ in the dry weight with the solubilization from the spore of dipicolinic acid, calcium and hexosamine-containing mucopeptide (Powell \& Strange, 1953; Strange \& Powell, 1954). During outgrowth, the germinated spore goes through stages of swelling and elongation, the developing vegetative bacillus finally emerging from the discarded outer layers of the spore and going through the first division.

Although there is evidence that the calcium is located in the spore core (Thomas, 1964 ; Knaysi, 1965), various authors have claimed that the dipicolinic acid, calcium and mucopeptide of the spore are located in the cortex (Mayall \& Robinow, 1957; Vinter, 1965; Warth, Ohye \& Murrell, 1963) and that the primary event in germination is a dissolution or alteration in the cortex structure (Kawata, Inoue \& Takagi, 1963; Mayall \& Robinow, 1957). A lytic enzyme capable of hydrolysing the spore mucopeptide has been described (Strange \& Dark, 1957) and extracted from Bacillus cereus (Strange \& Dark, 1957; Gould, 1962; Gould \& Hitchins, 1965). Although this lytic enzyme has not been extracted from $B$. subtilis, B. sphaericus or $B$. coagulans, there is evidence for its presence in the latter two species. Gould \& Hitchins (1965) suggested that a prime event in the germination of all species may be the activation of the lytic enzyme. The outgrowth characteristics of several Bacillus species have been examined (Lamanna, 1940; Gould, 1962). From this work the generalization can be made that species with 
large spores, e.g. B. cereus, grow out by dissolving away the coat and cortex layers over a large area of the cell surface, whereas with the species with small spores, e.g. $B$. subtilis, the outer layers of the spore split open and the vegetative bacillus emerges, leaving behind largely unaltered fragments of the spore integument. Although no evidence has been obtained of an enzyme which lyses the spore coats, the dissolution of the cortex during outgrowth could be explained by the lytic enzyme, acting over the whole cortex in $B$. cereus but only at a limited number of specific sites in $B$. subtilis (Gould, 1962).

Several studies of thin sections of spores in the electron microscope have been made. Chapman \& Zworykin (1957) examined germinating and growing Bacillus cereus and showed the gradual dissolution of the spore cortex and coat layers, with fragments of coat still attaching to the vegetative bacilli, even after the first division. Similar results were obtained from the study of $B$. anthracis (Moberley, Shafa \& Gerhardt, 1966). In their elegant study of B. subtilis, Kawata et al. (1963) described the multi-laminate structure of the coat and the undifferentiated appearance of the core in the mature spore. After germination, the cytoplasm of the core, or future vegetative bacillus, developed the characteristic granular appearance with a nuclear area of low electron density. As growth proceeded, the cortex was dissolved away and the vegetative bacillus developed its cell wall and membrane, and eventually grew out by rupturing the spore coat in the equatorial region. Similar findings have recently been reported by Rousseau, Fléchon \& Hermier (1966). By staining with lanthanum nitrate, Mayall \& Robinow (1957) were able to obtain a very clear picture of cortex structure in spores of $B$. megaterium. During germination the laminated structure loosened and the cortex became spongy. At the same time, the outer layer of the spore coat was thrown off and folded, and the core became granular. During growth the cortex disappeared, the normal cytoplasm, wall and membrane of the vegetative bacillus developed, and the spore coat dissolved away at the polar region to allow the emergence of the vegetative bacillus.

In this study we have examined the characteristic morphological changes during the germination and growth of Bacillus cereus and B. polymyxa spores, and compared these with the losses of dipicolinic acid, calcium and mucopeptide from the spores during germination, and the re-incorporation of the mucopeptide into the wall of the developing vegetative bacillus.

\section{METHODS}

Cultures and media. The two organisms used in this study were laboratory strains of Bacillus cereus and B. polymyxa. Bacillus cereus was the PX strain used by Strange \& Dark (1957) for the isolation of the lytic enzyme. These bacteria were grown on the surface of potato glucose agar containing $0.25 \%(\mathrm{w} / \mathrm{v})$ glucose, $0.4 \%(\mathrm{w} / \mathrm{v})$ yeast extract, $0.4 \%(\mathrm{w} / \mathrm{v})$ potato extract and $1.5 \%(\mathrm{w} / \mathrm{v})$ agar $(\mathrm{pH} 7 \cdot 4)$. After a large crop of free spores had been produced in 2-5 days at $30^{\circ}$, they were washed off the surface of the agar with ice-cold de-ionized water, washed clean from vegetative forms and agar particles by several centrifugations, heated for $30 \mathrm{~min}$. at $65^{\circ}$ and stored at $4^{\circ}$ in a suspension containing $10^{8}-10^{9}$ spores $/ \mathrm{ml}$. Before each experiment the spores were heat activated by heating at $65^{\circ}$ for $30 \mathrm{~min}$.

The germination medium for Bacillus cereus was $10 \mathrm{ml}$. spore suspension, $60 \mathrm{ml}$. $0.15 \mathrm{M}$-phosphate buffer ( $\mathrm{pH} 7 \cdot 6$ ), $15 \mathrm{ml}$. of $10 \mathrm{mg}$. alanine/ml. solution and $15 \mathrm{ml}$. 
of $10 \mathrm{mg}$. inosine $/ \mathrm{ml}$. solution. The germination medium for $B$. polymyxa was $10 \mathrm{ml}$. spore suspension, $240 \mathrm{ml} .0 \cdot 15 \mathrm{M}$-phosphate buffer ( $\mathrm{pH} 7 \cdot 6$ ) and $50 \mathrm{ml}$. of $10 \mathrm{mg}$. alanine $/ \mathrm{ml}$. solution. Incubation was for $1-2 \mathrm{hr}$ at $30^{\circ}$, until $95-100 \%$ germination had taken place, as assayed by loss of phase brightness. The extent of germination was verified by colony counts after heating to $65^{\circ}$ for $30 \mathrm{~min}$. to kill the germinated organisms. Control samples were obtained by making the above dilutions in de-ionized water, rather than in germination media. After germination the organisms were washed twice in icecold de-ionized water and resuspended to $30 \mathrm{ml}$.

Germination and outgrowth were followed by withdrawing samples at intervals from spore suspensions in a full nutrient medium containing $0.5 \%(\mathrm{w} / \mathrm{v})$ glucose, $0.5 \%$ (w/v) peptone, $0.5 \%(\mathrm{w} / \mathrm{v}) \mathrm{Na}_{2} \mathrm{HPO}_{4} .12 \mathrm{H}_{2} \mathrm{O}, 0.5 \%(\mathrm{w} / \mathrm{v})$ yeast extract and $0.5 \%$ (w/v) Lab Lemco ( $\mathrm{pH} 7 \cdot 3$ ). Seven ml. of spore suspension was added to $42 \mathrm{ml}$. preheated medium. Incubation was at $37^{\circ}$ with shaking, and $7 \mathrm{ml}$. samples were pipetted into $25 \mathrm{ml}$. ice-cold de-ionized water, centrifuged, washed in a further $15 \mathrm{ml}$. and finally resuspended to $3.5 \mathrm{ml}$. In this medium the germination of Bacillus cereus was so rapid that equivalent dilutions in de-ionized water had to be made in order to get a 'zero time' sample. A portion from each sample after washing was examined under the phase microscope and the stage of germination or outgrowth of the organisms noted.

Chemical analysis. Samples of dormant spores and spores germinated in the germination media were assayed in duplicate for dipicolonic acid $(5 \mathrm{ml}$.), calcium $(2 \mathrm{ml})$. and, as a measure of mucopeptide, hexosamine $(1 \mathrm{ml}$.). Only hexosamine assays were made on samples from full nutrient media. Dipicolinic acid was assayed by the method of Jansen, Lund \& Anderson (1958), after autoclaving the organisms at $121^{\circ}$ for $15 \mathrm{~min}$. Calcium was assayed by flame photometry after ashing the organisms at $500^{\circ}$ for $16 \mathrm{hr}$ and redissolving the residue in $6 \mathrm{ml} .0 .02 \mathrm{~N}-\mathrm{HCl}$. Hexosamine was assayed by a modification of the method of Boas (1953). The organisms were hydrolysed for $2 \mathrm{hr}$ at $100^{\circ}$ with an equal volume of $12 \mathrm{~N}-\mathrm{HCl}$; hydrolysis from 1 to $7 \mathrm{hr}$ solubilized the same amounts of hexosamine. A blank containing water and a set of standards were run with each assay. A second blank for each tube was used to which was added $1 \mathrm{ml}$. $2 \%$ (w/v) $\mathrm{Na}_{2} \mathrm{CO}_{3}$ instead of $1 \mathrm{ml}$. acetylacetone $(1 \% \mathrm{w} / \mathrm{v})$ in $2 \%(\mathrm{w} / \mathrm{v}) \mathrm{Na}_{2} \mathrm{CO}_{3}$ (Immers \& Vasseur, 1950); the reading obtained from this blank, from 2-8\% of the test, was substracted from the test. Provided great care was taken over the neutralization step, and the acetylacetone (redistilled) and $p$-dimethylaminobenzaldehyde solutions were freshly prepared each day, satisfactory reproducibility of the results was obtainable.

Electron microscopy. For the fixation of samples for electron microscopy two fixatives were used. With dormant and germinated spores of both Bacillus cereus and $B$. polymyxa the best results were obtained by using $2 \%(\mathrm{w} / \mathrm{v}) \mathrm{KMnO}_{4}$ for $90 \mathrm{~min}$. at $22^{\circ}$ (Mollenhauer, 1959). Outgrowing spores of $B$. cereus were also fixed with $2 \%(\mathrm{w} / \mathrm{v}) \mathrm{KMnO}_{4}$, but only for $60 \mathrm{~min}$. at $22^{\circ}$. Outgrowing spores of B. polymyxa were best fixed with gluteraldehyde $+\mathrm{OsO}_{4}$ and this fixative was used for these organisms and also for dormant and germinated $B$. polymyxa spores, to allow comparison with $\mathrm{KMnO}_{4}$-fixed samples. The pellet of organisms was resuspended in $5 \%(\mathrm{w} / \mathrm{v})$ glutaraldehyde in $0 \cdot 1 \mathrm{M}$-phosphate buffer $\left(\mathrm{pH} \mathrm{7 \cdot 3)}\right.$ for $90 \mathrm{~min}$. at $4^{\circ}$. The organisms were washed once in cold buffer and then resuspended in $1 \%(\mathrm{w} / \mathrm{v}) \mathrm{OsO}_{4}$ solution for $120 \mathrm{~min}$. at $4^{\circ}$. The composition of the $\mathrm{OsO}_{4}$ solution was $5 \mathrm{ml}$. of $0 \cdot 14$ M-veronal acetate buffer ( $\mathrm{pH} 9 \cdot 0), 7 \mathrm{ml}$. of $0 \cdot 1 \mathrm{~N}-\mathrm{HCl}, 0 \cdot 12 \mathrm{ml}$. of $2 \mathrm{M}-\mathrm{CaCl}_{2}$ and $13 \mathrm{ml}$. 
of $2 \%(\mathrm{w} / \mathrm{v}) \mathrm{OsO}_{4}$. Ten-ml. volumes of fixative solutions were used for $10^{8}-10^{9}$ organisms. After fixation the organisms were embedded in Epon 812, wet sectioned on a Porter Blum MT 2 microtome, stained with $1 \%$ uranyl acetate for $10 \mathrm{~min}$. and examined in a JEM $6 \mathrm{~S}$ electron microscope.

\section{RESULTS}

The amounts of dipicolinic acid, calcium and hexosamine in the dormant spores of Bacillus cereus and B. polymyxa, are recorded in Table 1 , with the percentages lost on germination in the germination media.

Table 1. Amounts of dipicolinic acid, calcium, and hexosamine in dormant spores of Bacillus cereus and B. polymyxa, and the percentages lost on germination

$\begin{array}{llcc} & & \begin{array}{c}\% \text { of } \\ \text { spore } \\ \text { dry wt. }\end{array} & \begin{array}{c}\% \text { lost } \\ \text { on germination }\end{array} \\ & \text { Dipicolinic acid } & 8 \cdot 4 & 95-100 \\ & \text { Calcium } & 4 \cdot 5 & 63 \\ & \text { Hexosamine } & 6 \cdot 8 & 32 \\ & \text { Dipicolinic acid } & 8 \cdot 5 & 95-100 \\ & \text { Calcium } & 3 \cdot 5 & 69 \\ & \text { Hexosamine } & 7 \cdot 3 & 41\end{array}$

Table 2. Stages of germination and outgrowth of Bacillus cereus

Time of incubation (min.) spores incubated in nutrient medium

$\begin{array}{cc}\text { (min.) } & \text { Stage of development } \\ 0 & 99 \% \text { phase-bright, } 1 \% \text { dark } \\ 10 & 20 \% \text { phase-bright, } 80 \% \text { dark } \\ 20 & 14 \% \text { phase-bright, } 86 \% \text { dark } \\ 30 & 15 \% \text { phase-bright, } 85 \% \text { dark } \\ 40 & 15 \% \text { phase-bright, } 85 \% \text { dark } \\ 50 & 10 \% \text { phase-bright, } 90 \% \text { dark } \\ 60 & 12 \% \text { phase-bright, } 88 \% \text { dark }\end{array}$

$1.0 \times 1.0 \mu$
$2.0 \times 1.5 \mu$
$60 \%$ elongated to $3.0 \times 1.5 \mu$
$70 \%$ elongated to $3.0 \times 1.5 \mu$
$70 \%$ elongated to $4.0 \times 1.5 \mu$
$85 \%$ elongated to $5.0 \times 1.5 \mu$
$40 \%$ elongated to $6.0 \times 1.5 \mu, 40 \%$ out-
growing from spore coats, and $20 \%$
dividing vegetative forms

Table 3. Stages of germination and outgrowth of Bacillus polymyxa spores incubated in nutrient medium

Time of incubation (min.) Stage of development

$\begin{array}{rl}0 & 100 \% \text { phase-bright } \\ 35 & 31 \% \text { phase-bright, } 69 \% \text { dark } \\ 70 & 31 \% \text { phase-bright, } 45 \% \text { dark and swollen, } 20 \% \text { showing early outgrowth, } \\ & 4 \% \text { vegetative forms } \\ 90 & 33 \% \text { phase-bright, } 19 \% \text { dark and swollen, } 8 \% \text { showing early outgrowth, } \\ & 33 \% \text { outgrown, } 8 \% \text { vegetative forms } \\ 120 & 33 \% \text { phase-bright, } 7 \% \text { dark and swollen, } 6 \% \text { showing early outgrowth, } \\ & 5 \% \text { outgrown, } 45 \% \text { vegetative forms }\end{array}$

The stages of germination and outgrowth reached by the organisms after incubation for fixed times in the full nutrient medium are shown in Tables 2 and 3. After $10 \mathrm{~min}$. Bacillus cereus spores had germinated; with spores of $B$. polymyxa this took $35 \mathrm{~min}$. 
Largely because of the higher concentrations of organisms used with the full nutrient medium, a large proportion of the spores remained dormant throughout the period of incubation; i.e. $10-15 \%$ of $B$. cereus and $30-33 \%$ of $B$. polymyxa. During outgrowth of $B$. cereus spores, the phase-dark organisms first swelled slightly and then elongated to 6 times the length of the dormant spore, before finally growing out from as much of the exosporium and spore coats as remained. On the other hand, B. polymyxa spores swelled slightly, and then changed to a crescent shape before early growth was evident from the distortion at the central portion of the outside surface of the crescent. The organisms were considered to have grown out when the virtually complete vegetative bacillus was seen with the spore integument still clearly visible, generally as a figure 3 at one end of the rod. After the first division occurred the organisms were said to be vegetative.

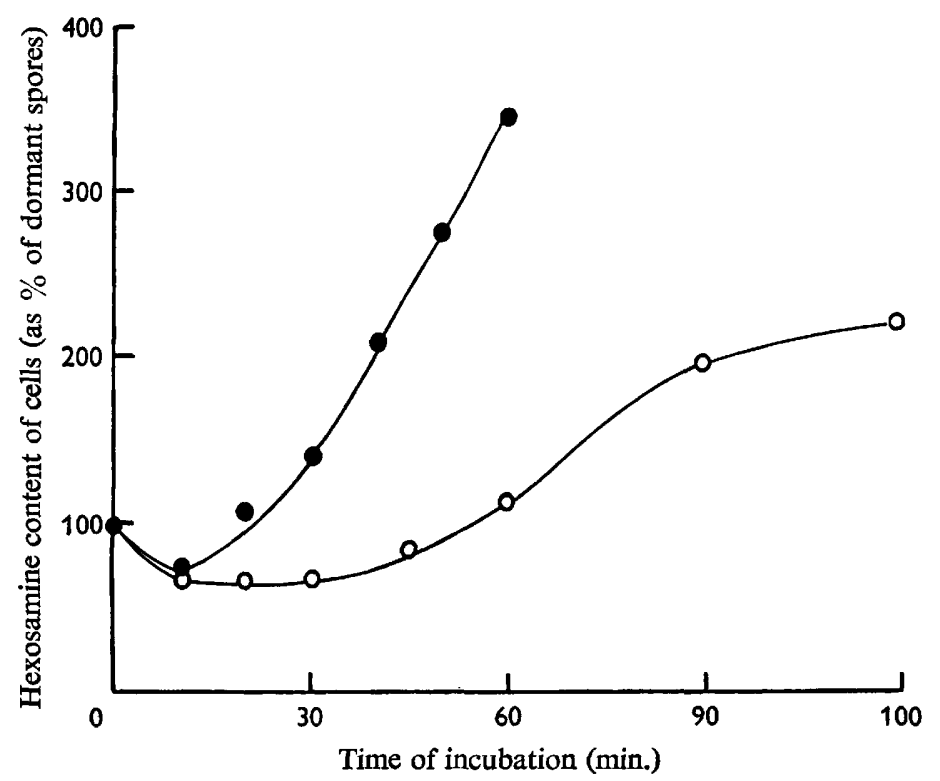

Fig. 1. Hexosamine content of Bacillus cereus and B. polymyxa spores incubated in nutrient medium. The results are expressed as percentages, the hexosamine content of the dormant spore being taken as $100 \%$. O, B. cereus; O, B. polymyxa.

The results in Fig. 1 show the hexosamine content of organisms taken from incubations in the nutrient medium. Under these conditions, the loss of hexosamine associated with germination was $30 \%$ for Bacillus cereus and $33 \%$ for $B$. polymyxa. These values agree favourably with the values of $32 \%$ and $41 \%$, respectively, for germination in the chemically defined germination media (Table 1). From Fig. 1 we can see that the re-incorporation and resynthesis of mucopeptide associated with the cell-wall synthesis of the vegetative form had begun after $10 \mathrm{~min}$. with $B$. cereus and after $30 \mathrm{~min}$. with $B$. polymyxa, i.e. immediately after germination was completed.

Rode, Lewis \& Foster (1962) showed the effectiveness of $\mathrm{KMnO}_{4}$ as a fixative for dormant spores; in our hands also this fixative gave satisfactory results with these organisms. In contradiction with these authors, however, the cortex was clearly visible in our $\mathrm{KMnO}_{4}$ preparations. Although $\mathrm{KMnO}_{4}$ proved the best fixative for Bacillus 
cereus throughout germination and outgrowth, the most satisfactory results with $B$. polmyxa after germination were obtained using glutaraldehyde $+\mathrm{OsO}_{4}$.

On P1. 1 and 2, fig. 1-8, are shown spores of Bacillus cereus taken from samples incubated in nutrient medium. Plate 1, fig. 1, shows a spore with the exosporium, three spore coats, cortex, cortical membrane or core wall, core or plasma membrane, and core, all clearly visible. There is evidence of a laminated structure in the exosporium and in the middle spore coat, and a very definite laminated structure in the inner coat. The outer coat appears much more granular in its structure. Between the inner spore coat and the cortex there is a dark diffuse layer. The core is bounded by a plasma membrane of characteristic unit membrane structure, and the core wall is also present. The core itself appears as a uniform dense background with areas containing collections of large granules approximately $100 \AA$ in diameter. There is no evidence of any nuclear area.

Plate 1, fig. 2 and 3, show spores after 2 and $10 \mathrm{~min}$. incubation in the nutrient medium. Germination occurred very rapidly and was associated with the following changes in structure. The cortex has disappeared entirely and the core swollen to fill the whole volume of the cell inside of the spore coats. The organization of the core has altered to show the granular network of ribosomes characteristic of the vegetative form. In Pl. 1, fig. 3 the development has proceeded further and nuclear areas are evident in the cytoplasm; also, the spore coats have drawn away slightly from the core or developing vegetative form. The cytoplasm is bounded solely by the plasma membrane and there is no evidence for the continued existence of the core wall. This separation of the plasma membrane from the spore coats is more evident after $30 \mathrm{~min}$. (Pl. 1, fig. 4). At this stage we can also see the extensive dissolution of the outer and middle spore coats.

Plate 1, fig. 5 and Pl. 2, fig. 6 and 7 show outgrowing forms of Bacillus cereus after 40 and $60 \mathrm{~min}$. When the inner spore coat begins to dissolve away, the cell wall and plasma membrane are both present in the outgrowing form. The cortex and middle spore coat are completely absent and, depending on the section, fragments of the inner coat, or inner and outer coats, or both coats plus the exosporium, are seen round one end only of the outgrowing form. Plate 2, fig. 8 shows an example of the integument fragments left behind by the outgrown forms.

On Pl. 3 and 4, fig. 9-16 are a similar series of pictures of germinating and outgrowing spores of Bacillus polymyxa. The only differences evident between the $B$. polymyxa spore (Pl. 3, fig. 9) and the $B$. cereus spore (Pl. 1, fig. 1) are in the exosporium and spore coats. Bacillus polymyxa lacks an exosporium and has a very different coat structure. The smooth outer surface consists of a bimolecular leaflet type structure, beneath which lies an undifferentiated area and then a highly structured layer of at least 6 bimolecular leaflets or laminates. Between this highly structured layer and the cortex there is the dark structureless layer which is also seen in B. cereus spores. The cortex, core wall, plasma membrane and core are the same as those found in $B$. cereus.

Plate 3, fig. 10 shows that in Bacillus polymyxa the only changes which occur with germination are in the core, which develops the characteristic granular appearance of the cytoplasm of the vegetative form and a nuclear area. This picture was taken from spores germinated in the chemically defined germination medium, but the same changes were noted in spores germinated by $35 \mathrm{~min}$. incubation in the full nutrient medium. 
Plates 3 and 4, fig. 11-16 show preparations (fixed with glutaraldehyde $+\mathrm{OsO}_{4}$,) of spores germinated in the germination medium, and of spores growing out after 50, 70 and $90 \mathrm{~min}$. in the nutrient medium. Comparing fig. 11 and 12 with fig. 9 and 10 on Pl. 3, we can see that this method of fixation shows less structure in the spore coat and core, but gives a very good picture of the cortex, core wall and plasma membrane. The cortex appears to consist of two layers clearly separated from each other by a dark line. Again the only observable difference after germination is in the core organization. Plate 3, fig. 13 and 14 show organisms at the stage of early outgrowth. The coat and cortex, still apparently largely unaltered, are splitting open at one site in the equatorial region. As this process continues, the core wall develops from a thin dark line to the complete cell wall of the vegetative form in the almost fully outgrown organism in Pl. 4, fig. 15. Plate 4, fig. 16 shows an outgrown form in which the coat and cortex layers appear to have split open round the entire equator. Even with these fully outgrown forms, some cortical material is still present in the spore integument, although a gradual dissolution of the cortex structure can be seen in the development of germinated to outgrown forms.

\section{DISCUSSION}

These series of electron micrographs show the different characteristics of the germination and outgrowth of Bacillus cereus and B. polymyxa spores. The results with $B$. cereus are in good agreement with the findings of Gould (1962) and Chapman \& Zworykin (1957), and B. polymyxa shows all the established characteristics of smallspored species such as $B$. subtilis (Gould, 1962). In particular, there is excellent agreement between our own results and those of Kawata et al. (1963), and Rousseau et al. (1966).

The cell wall of the vegetative form of Bacillus polymyxa clearly develops directly from the core wall of the spore, although the situation is not so clear cut with $B$. cereus where the core wall seems to disappear along with the cortex during germination. In this connexion it is interesting to note there is no evidence of cell-wall synthesis in thin sections of $B$. cereus until after $40 \mathrm{~min}$. incubation in the nutrient medium, although the hexosamine content of the organisms began to increase again after only 10 min. incubation (Fig. 1). With B. polymyxa, the cell wall of the vegetative form is not evident in thin sections until after $50 \mathrm{~min}$., although the hexosamine content of the organisms began to increase after $30 \mathrm{~min}$.

It has been claimed that the dipicolinic acid, calcium and mucopeptide of the spore are located in the cortex (Mayall \& Robinow, 1957; Warth et al. 1963; Vinter, 1965) and that a prime event in germination is a dissolution of the cortex structure (Mayall \& Robinow, 1957; Kawata et al. 1963). Our findings on the loss of these components from germinated spores of both Bacillus cereus and B. polymyxa (Table 1) are in agreement with these hypotheses. However, although the solubilization of the diplicolinic acid, calcium and mucopeptide was associated with the disappearance of the cortex in germinated B. cereus ( $\mathrm{Pl}$. 1, fig. 2), the same process in B. polymyxa caused no apparent alteration in its cortical structure (Pl. 3, figs. 10 and 12). With both spores, however, only $30-40 \%$ of the total mucopeptide was solubilized on germination. The $70-60 \%$ which was retained by the organisms seems therefore to have a function quite separate from that of preserving spore dormancy. From our data, this retained mucopeptide 
must be entirely or very largely in the exosporium of $B$. cereus, but in the core wall and cortex of $B$. polymyxa.

Although these data do not allow us to suggest any mechanism whereby the mucopeptide, and dipicolinic acid and calcium, preserve spore dormancy, they do serve to highlight the fact that only a certain proportion of the mucopeptide is directly involved in this dormancy, and to illustrate that, while the changes in chemical structure and biological activity associated with germination are virtually identical in the two species, the morphological changes are quite different.

In studies of germination it has been assumed that the only materials lost from the spore are dipicolinic acid, calcium and mucopeptide. Powell \& Strange (1953) showed that Bacillus megaterium spores lost $30 \%$ of their dry weight on germination, and in our studies we have noted weight losses from $30 \%$ to $50 \%$. On the basis of present data (Murrell \& Warth, 1965) hexosamine can be taken to represent approximately $50 \%$ of the weight of the spore mucopeptide. From the data in Table 1 we see that the loss of dipicolinic acid, calcium and mucopeptide during germination of $B$. cereus amounted to only $16 \%$ of the dry weight of the spore, and of $B$. polymyxa to $17 \%$. It would appear therefore that dipicolinic acid, calcium and mucopeptide cannot be the only materials lost from the spore on germination.

The authors are grateful to Miss L. F. Parkin for skilled technical assistance.

\section{REFERENCES}

BoAs, N. F. (1953). Method for the determination of hexosamine in tissues. J. biol Chem. 204, 953.

CHAPMAN, G. B. \& ZWORYKIN, K. A. (1957). Study of germinating Bacillus cereus spores employing television microscopy of living cells and electron microscopy of ultrathin sections. J. Bact. 74, 126.

Gould, G. W. (1962). Microscopical observations on the emergence of cells of Bacillus spp. from spores under different cultural conditions. J. appl. Bact. 25, 35.

Gould, G. W. \& HITCHINs, A. D. (1965). Germination of spores with Strange and Dark's spore lytic enzyme. In Spores. Ed. by L. L. Campbell and H. O. Halvorson, vol. III, p. 213. Ann Arbor: American Society for Microbiology.

IMMERS, J. \& VASSEUR, E. (1950). Influence of sugars and amines on the colorimetric hexosamine method of Elson and Morgan and its possible elimination. Nature, Lond. 265, 898.

J ANSSEN, F. W., LUND, A. J. \& ANDERSON, L. E. (1958). Colorimetric assay for dipicolinic acid in bacterial spores. Science, N.Y. 127, 26.

KaWATA, T., INoue, T. \& TAKagI, A. (1963). Electron microscopy of spore formation and germination in Bacillus subtilis. Japan. J. Microbiol. 7, 23.

KNAYSI, G. (1965). Further observations on the spodogram of Bacillus cereus endospore. J. Bact. 90, 453.

Lamanna, C. (1940). The taxonomy of the genus Bacillus. 1. Modes of spore germination. J. Bact. 40, 347.

MAYALl, B. H. \& RoBiNow, C. F. (1957). Observations with the electron microscope on the organization of the cortex of resting and germinating spores of $B$. megaterium. J. appl. Bact. 20, 333.

Moberley, B. J., Shafa, F. \& Gerhardt, P. (1966). Structural details of anthrax spores during stages of transformation into vegetative cells. J. Bact. 92, 220.

Mollenhauer, H. M. (1959). Permanganate fixation of plant cells. J. biophys. biochem. Cytol. 6, 431.

MurRell, W. G. \& WARTH, A. D. (1965). Composition and heat resistance of bacterial spores. In Spores. Ed. by L. L. Campbell and H. O. Halvorson, vol. 1II, p. 1. Ann Arbor: American Society for Microbiology.

Powell, J. F. \& Strange, R. E. (1953). Biochemical changes occurring during the germination of bacterial spores. Biochem. J. 54, 205.

RODE, L. J., LeWIS, C. W. \& Foster, J. W. (1962). Electron microscopy of spores of Bacillus megaterium with special reference to the effects of fixation and thin sectioning. J. cell. Biol. 13, 423.

Rousseau, M., FlÉCHON, J. \& HermiER, M. (1966). Étude au microscope électronique de la germination de la spore chez Bacillus subtilis. Ann. Inst. Pasteur 111, 149. 
Journal of General Microbiology, Vol. 47, No. 1

Plate 1
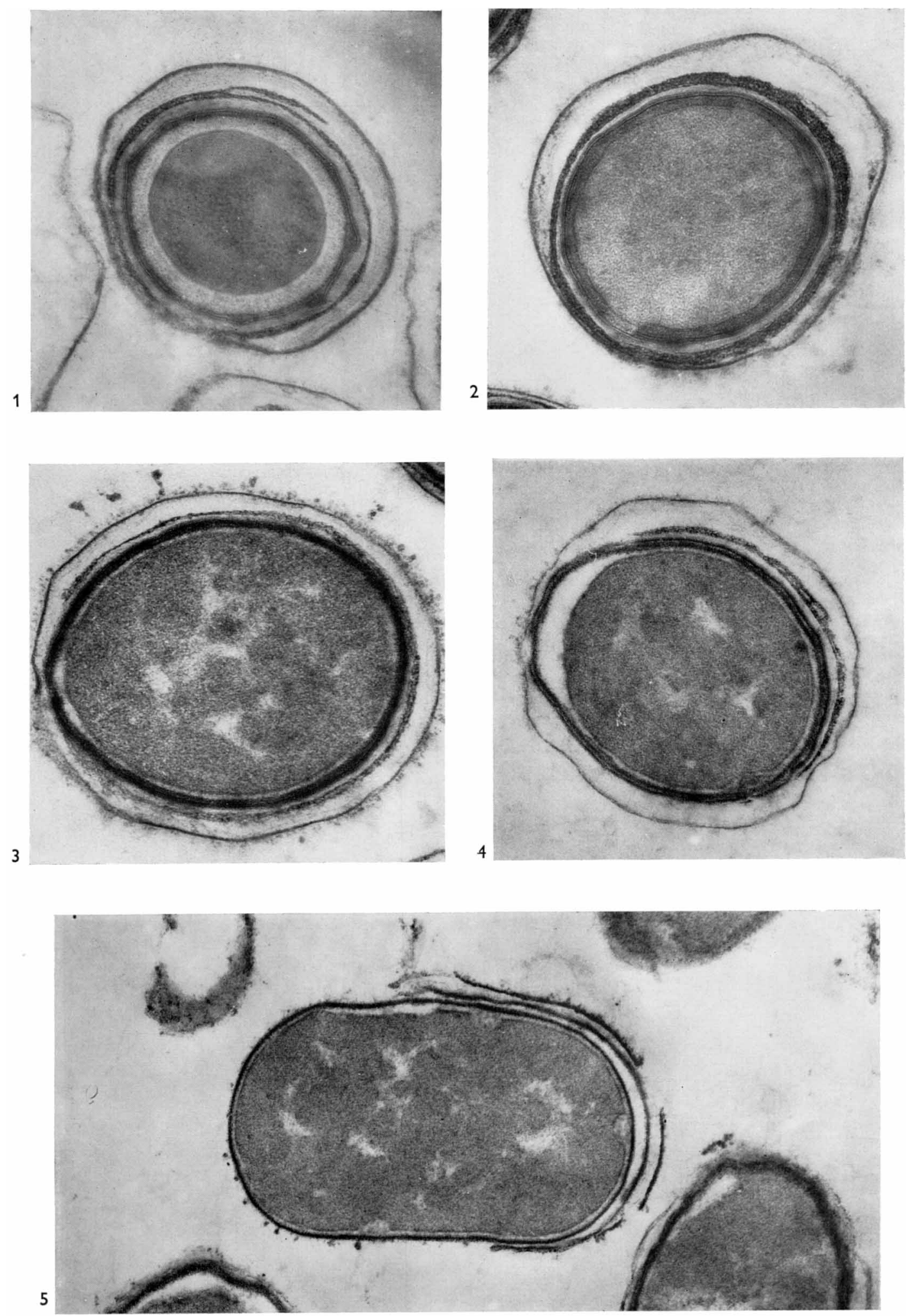
Journal of General Microbiology, Vol. 47, No. 1

Plate 2
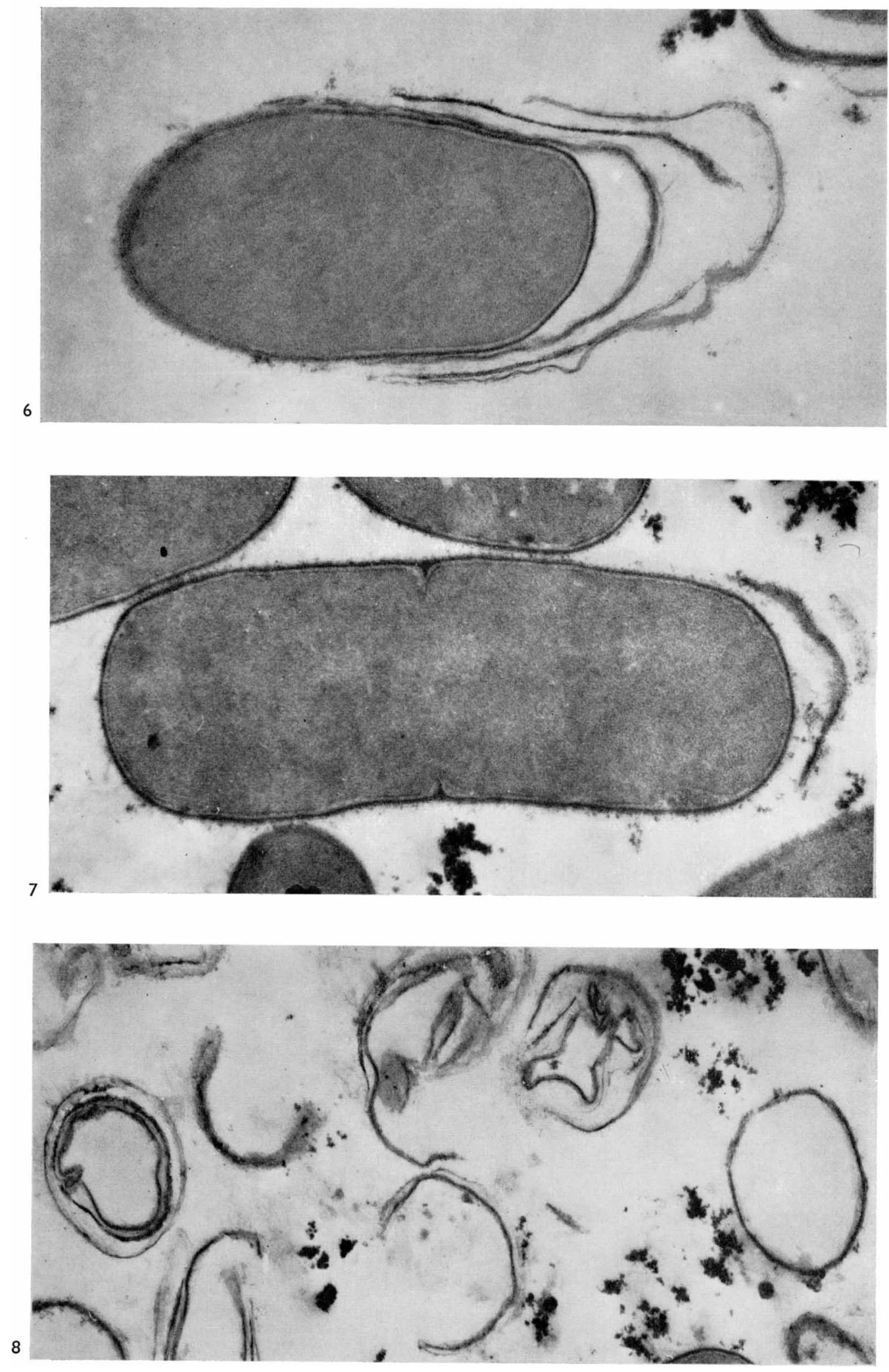

W. A. HAMILTON AND J. M. STUBBS 

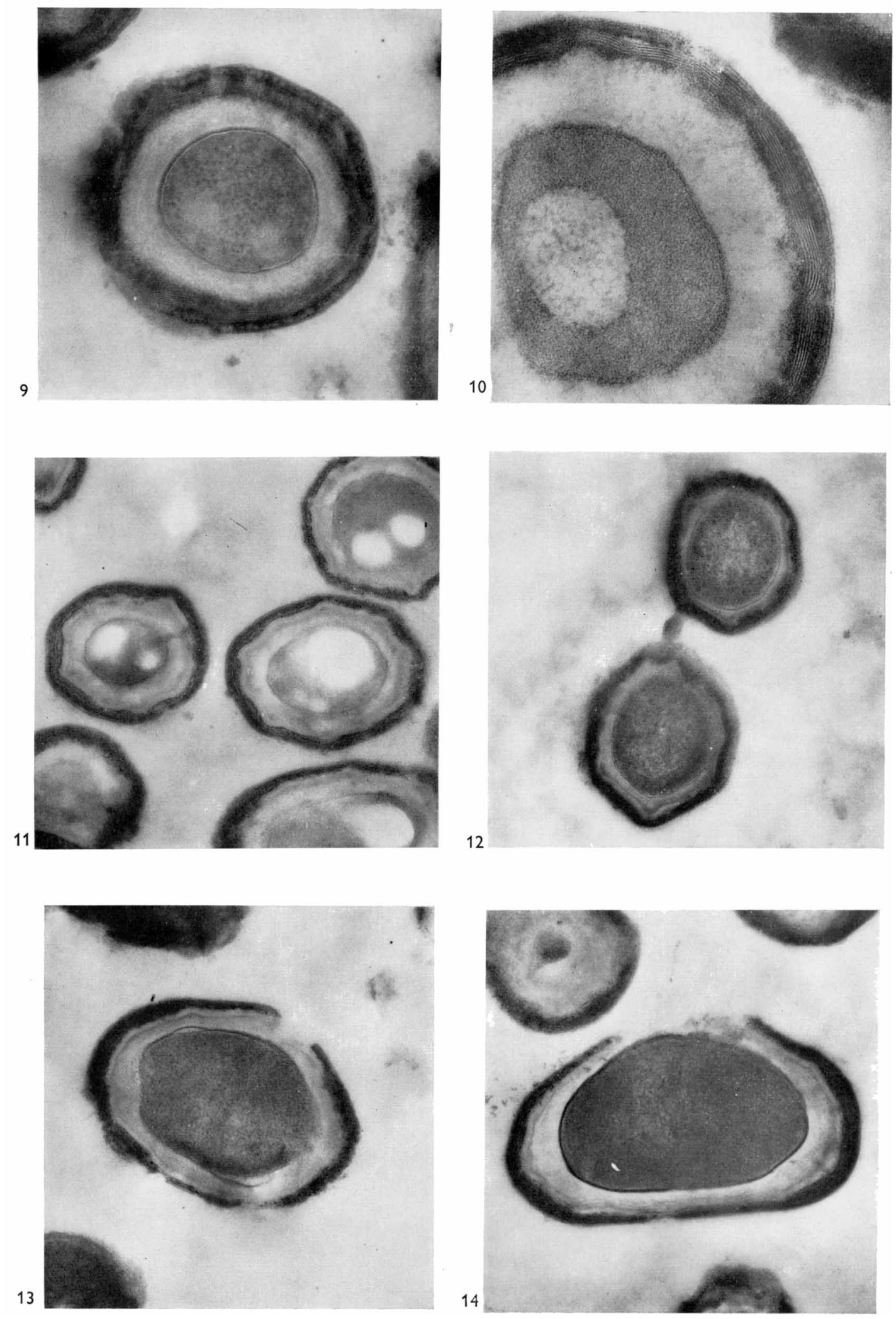

W. A. HAMILTON AND J. M. STUBBS 

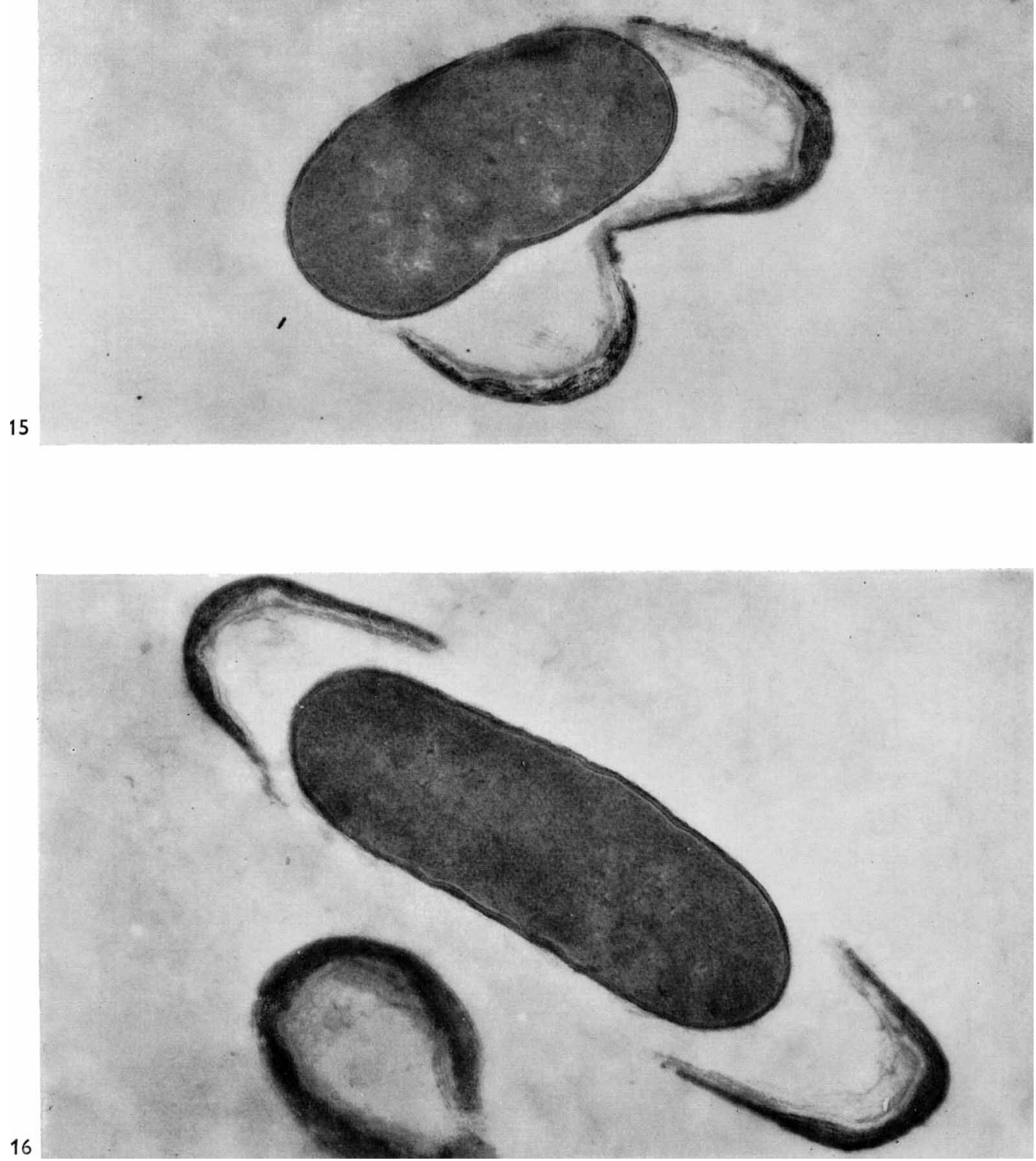

W. A. HAMILTON AND J. M. STUBBS 
Strange, R. E. \& Dark, F. A. (1957). A cell-wall lytic enzyme association with spores of Bacillus species. J. gen. Microbiol. 16, 236.

Strange, R. E. \& Powell, J. F. (1954). Hexosamine-containing peptides in spores of Bacillus subtilis, $B$. megaterium and B. cereus. Biochem. J. 58, 80 .

Thomas, R. S. (1964). Ultrastructural localization of mineral matter in bacterial spores by microincineration. J. cell. Biol. 23, 113.

VINTER, V. (1965). Spores of microorganisms. XVII. The fate of preexisiting diaminopimelic acidcontaining structures during germination and postgerminative development of bacterial spores. Folia Microbiol. 10, 280.

Warth, A. D., OhYe, D. F. \& MurRell, W. G. (1963). Location and composition of spore mucopeptide in Bacillus species. J. cell. Biol. 16, 593.

\section{EXPLANATION OF PLATES}

\section{Plate 1}

Fig. 1. Thin section of Bacillus cereus. Dormant spore; $\mathrm{KMnO}_{4}$ fixed. $\times 60,000$.

Fig. 2. Thin section of $B$. cereus. Germinated spore after $2 \mathrm{~min}$. incubation in nutrient medium; $\mathrm{KMnO}_{4}$ fixed. $\times 60,000$.

Fig. 3. Thin section of $B$. cereus. Germinated spore after $10 \mathrm{~min}$. incubation in nutrient medium; $\mathrm{KMnO}_{4}$ fixed. $\times 60,000$.

Fig. 4. Thin section of $B$. cereus. Germinated spore after $30 \mathrm{~min}$. incubation in nutrient medium; $\mathrm{KMnO}_{4}$ fixed. $\times 60,000$.

Fig. 5. Thin section of $B$. cereus. Outgrowing spore after $40 \mathrm{~min}$. incubation in nutrient medium; KMnO، fixed. $\times 40,000$.

\section{Plate 2}

Fig. 6. Thin section of Bacillus cereus. Outgrowing spore after $40 \mathrm{~min}$. incubation in nutrient medium; $\mathrm{KMnO}_{4}$ fixed. 40,000 .

Fig. 7. Thin section of $B$. cereus. Outgrown form after $60 \mathrm{~min}$. incubation in nutrient medium; $\mathrm{KMnO}_{4}$ fixed. $\times 40,000$.

Fig. 8. Thin section of $B$. cereus. Spore integuments left by outgrown forms; $\mathrm{KMnO}_{4}$ fixed. $\times 20,000$.

\section{Plate 3}

Fig. 9. Thin section of Bacillus polymyxa. Dormant spore; $\mathrm{KMnO}_{4}$ fixed. $\times 70,000$.

Fig. 10. Thin section of B. polymyxa. Spore germinated in chemically defined germination medium; $\mathrm{KMnO}_{4}$ fixed. $\times 87,500$.

Fig. 11. Thin section of $B$. polymyxa. Dormant spore; glutaraldehyde $+\mathrm{OsO}_{4}$ fixed. $\times 40,000$.

Fig. 12. Thin section of $B$. polymyxa. Spore germinated in chemically defined germination medium; glutaraldehyde $+\mathrm{OsO}_{4}$ fixed. $\times 40,000$.

Fig. 13. Thin section of B. polymyxa. Outgrowing spore after $50 \mathrm{~min}$. incubation in nutrient medium; glutaraldehyde $+\mathrm{OsO}_{4}$ fixed. $\times 40,000$.

Fig. 14. Thin section of B. polymyxa. Outgrowing spore after $70 \mathrm{~min}$. incubation of nutrient medium; glutaraldehyde $+\mathrm{OsO}_{4}$ fixed. $\times 40,000$.

\section{Plate 4}

Fig. 15. Thin section of Bacillus polymyxa. Outgrowing spore after $90 \mathrm{~min}$. incubation in nutrient medium; glutaraldehyde $+\mathrm{OsO}_{4}$ fixed. $\times 40,000$.

Fig. 16. Thin section of $B$. polymyxa. Outgrowing spore after $90 \mathrm{~min}$ incubation in nutrient medium; glutaraldehyde $+\mathrm{OsO}_{4}$ fixed. $\times 40,000$. 